\title{
Cytokine interactions with epithelium
}

\author{
KIM E BARRETT PhD
}

\begin{abstract}
KE BARRETT. Cytokine interactions with epithelium. Can J Gastroenterol 1996;10(5):323-328. Cytokines are a family of proteins that serve as intracellular messengers within the immune system and as growth factors for several cell types. Recent studies indicate that intestinal inflammation is accompanied by increases in a wide variety of cytokines and growth factors. Current knowledge in the area of cytokine-epithelial interactions, with particular reference to the involvement of such interactions in intestinal inflammation, is reviewed. Topics include epithelial functions subject to modulation by cytokines; effects of cytokines on epithelial damage, restitution and proliferation; effects of cytokines on the ability of the epithelium to express immune accessory and adhesion molecules; and effects of cytokines on the production of inflammatory mediators by the epithelium.
\end{abstract}

Key Words: Cytokines, Epithelium, Inflammation

\section{Interaction des cytokines avec l'épithélium}

RÉSUMÉ : Les cytokines sont une famille de protéines qui agissent à titre de messagers intracellulaires pour le système immunitaire et à titre de facteurs de croissance pour divers types cellulaires. De récentes études indiquent que l'inflammation intestinale s'accompagne d'augmentations d'une grande variété de cytokines et de facteurs de croissance. Les récents progrès enregistrés dans le domaine des interactions cytokine-épithélium, particulièrement en ce qui a trait à la participation de ces interactions dans l'inflammation intestinale, sont passés en revue ici. Les thèmes abordés sont entre autres, les fonctions de l'épithélium influencées par les cytokines, les effets des cytokines sur les lésions épithéliales, la réparation et la prolifération, les effets des cytokines sur la capacité de l'épithélium à exprimer les molécules immunitaires accessoires et adhésives et les effets des cytokines sur la production des médiateurs de l'inflammation par l'épithélium.
$\mathrm{C}$ ytokines are a family of proteins that serve as intracellular messengers within the immune system and as growth factors for several cell types. Recent studies indicate that intestinal inflammation is accompanied by increases in a wide variety of cytokines and growth factors (reviewed in 1 ). Because the intestinal epithelium is a frequent target of the inflammatory process in diseases such as Crohn's disease and ulcerative colitis, whether epithelial functions are modulated by cytokines has been examined. Indeed, many cytokines and growth factors have been shown to alter a spectrum of epithelial functions (Table 1). Another area of research receiving considerable attention is the possibility that the epithelium acts not only as a target of intestinal inflammation, but also as an active participant in the overall inflammatory response. In part, this participation may result from the ability of epithelial cells to express adhesion and accessory molecules, and to synthesize inflammatory mediators such as eicosanoids. Both properties may be subject to cytokine regulation. Other recent data suggest that the epithelium can act as a source of some cytokines. The ability of the epithelium to produce both eicosanoids and proinflammatory cytokines may represent one segment of an autocrine loop whereby inflammatory dysfunction of the epithelium is amplified. Recent progress in the area of cytokine-epithelial interactions, with particular reference to the involvement of such interactions in intestinal inflammation, is reviewed. By drawing on the findings of a number of laboratories, an integrated overview of the epithelial functions that may be subject to regulation by cytokines and growth factors is provided.

Division of Gastroenterology, Department of Medicine, University of California and School of Medicine, San Diego, California

Correspondence: Dr Kim E Barrett, UCSD Medical Center, 8414, 200 West Arbor Drive, San Diego, CA 92103-8414, USA. Telephone 619-543-3726, fax 619-543-6969, e-mail kbarrett@ucsd.edu

This paper was presented at the Basic Research and Clinical Implications in IBD meeting, April 6 to 9, 1994, held in Victoria, British Columbia. This paper has also been published in Sutherland LR, et al, eds. Inflammatory Bowel Disease: Basic Research, Clinical Implications and Trends in Therapy. Boston, Dordrecht and London: Kluwer Academic Publishers, 1994 
TABLE 1

\section{Epithelial functions subject to regulation by cytokines and growth factors}

\begin{tabular}{lc}
\hline Function & Implicated cytokines \\
\hline Ion transport & IL-1, IL-3, TGF- $\beta$, EGF \\
Paracellular permeability & IFN- $\gamma$, IGF-1 \\
Restitution and proliferation & IL-1, EGF, TGF- $\alpha$, \\
& TGF- $\beta$ \\
$\begin{array}{l}\text { Viability } \\
\text { Expression of adhesion and accessory } \\
\text { molecules }\end{array}$ & IL-1, IL-6, TNF- $\alpha$, IFN- $\gamma$ \\
$\begin{array}{l}\text { Production of cytokines and other } \\
\text { inflammatory mediators }\end{array}$ & IL-1, IL-6, TGF- $\beta$, \\
\hline
\end{tabular}

EGF Epidermal growth factor; IFN Interferon; IGF Insulin-like growth factor; IL Interleukin; TNF Tumour necrosis factor

\section{EPITHELIAL FUNCTIONS SUBJECT TO MODULATION BY CYTOKINES}

Effects of cytokines on epithelial transport properties: A primary function of the intestinal epithelium is to control the movement of electrolytes and other solutes (2). This function, which is responsible for the control of luminal water content, is achieved via the regulation of two main pathways: transcellular transport, whereby electrolytes and nutrients are actively transported across cells, and the paracellular pathway, controlled by intercellular tight junctions. A classical view of the regulation of active ion transport across the intestinal epithelium recognized three main regulatory systems: paracrine regulation by adjacent endocrine cells located within the epithelium; endocrine regulation involving bloodborne hormones from distant sites; and neurocrine regulation via the release of stimulatory and inhibitory neurotransmitters by nerves within the enteric nervous system. However, over the past 10 years it has become apparent that a fourth regulatory system should be added to this list, that of the intestinal immune system (3). Studies - both in vivo and in vitro - in humans and experimental animals have revealed that the release of inflammatory and immune mediators can be a prominent stimulus leading to transepithelial chloride secretion in the mammalian gastrointestinal tract. Because active secretion of chloride is the primary driving force for secretory diarrhea, the hypothesis has arisen that the ability of various immune and inflammatory mediators to evoke chloride secretion, perhaps in concert with agonists from other regulatory systems (such as the enteric nervous system [3]), is the primary pathophysiological mechanism underlying diarrhea associated with intestinal inflammation. In this context, a number of investigators have examined the ability of various cytokines to modify chloride secretary responses of the epithelium.

There is evidence that chloride transport may be stimulated by various cytokines. However, in contrast to the secretory effects of various other inflammatory mediators (including histamine, adenosine, prostaglandins and certain reactive oxygen species), the stimulatory effects of cytokines on chloride secretion appear to be primarily indirect and to require the participation of secondary mediators released from nonepithelial cell types. This conclusion is based on the fact that cytokines examined to date do not appear to evoke chloride secretion directly when added acutely to intestinal epithelial cell lines. Secretory effects have been noted, however, when certain cytokines are added to intact intestinal preparations. Addition of interleukin-1 (IL-1) or IL-3 to segments of chicken intestine mounted in Ussing chambers led to a rapid increase in chloride secretion (4). This effect, however, was blocked by a cyclo-oxygenase inhibitor, suggesting that it involved the secondary generation of prostaglandins, which then acted as the final stimulus for chloride secretion acting at the level of the secretory epithelial cells.

Similarly, the stimulatory effects of cytokines on chloride secretion may not be acute, but may involve delayed upregulation of responsiveness to other neurohormonal stimuli. This was found to be the case for a stimulatory effect of transforming growth factor-beta (TGF- $\beta$ ) on chloride secretion by the $T_{84}$ intestinal epithelial cell line, where the effect of the cytokine was to potentiate responses to vasoactive intestinal polypeptide (VIP) after $24 \mathrm{~h}$ of preincubation (5). Further, IL-1 can chronically up-regulate the ability of fibroblasts to deliver a paracrine signal for the stimulation of chloride secretion by the epithelium (6).

Cytokines and growth factors may also have negative effects on chloride secretion, positive effects on absorptive mechanisms or both. In the case of TGF- $\beta$, an inhibitory effect of chronic exposure on responses to the cAMP-dependent agonist VIP or direct elevation of intracellular cAMP levels with a cell-permeant cAMP analogue was noted in some $\mathrm{T}_{84}$ cell monolayers, which contrasts with the stimulatory effect of this cytokine described above (5). Whether a stimulatory or an inhibitory effect was observed appeared to depend, at least to some extent, on the overall level of responsiveness of the monolayers. Thus, when cells displayed an inhibition of chloride secretion after TGF- $\beta$ treatment, other monolayers examined in parallel were more likely to have a higher level of responsiveness to VIP under control conditions. These findings indicate that factors intrinsic to the epithelium may quantitatively or even qualitatively define the response of the epithelium to a given cytokine. Another cytokine capable of acting as an antisecretagogue is epidermal growth factor (EGF). This factor has been shown to enhance nutrient absorptive mechanisms in the small intestine (7), apparently by rapidly increasing the surface area of absorptive cells via an effect directed to the microvilli (8). EGF also specifically down-regulates calcium-dependent chloride secretion, an action that may be related to the prolonged generation of a putative second messenger for this process, inositol (3-6) tetrakisphosphate (9). Overall, these antisecretory effects of TGF- $\beta$ and EGF may represent an adaptive response of the epithelium. Conversely, diarrhea may result if a normal inhibitory tone, provided by the influence of agonists such as EGF, is lost in the setting of disease.

In addition to the regulation of active transport mechanisms in the intestinal epithelium, intestinal fluid and electrolyte balance are modulated by the dynamic regulation of 
paracellular permeability pathways, via the regulation of intercellular tight junctions. Cytokines may also regulate these paracellular transport pathways. Interferon-gamma (IFN- $\gamma$ ), insulin and insulin-like growth factors significantly reduce transepithelial resistance and thus enhance permeability to small solutes (10-14). The effect of these substances on epithelial resistance is slow in onset, and appears to require the synthesis of new proteins within the epithelial cell. In general, the effects of these agents appear to be limited to increasing epithelial permeability to small solutes and electrolytes. No evidence to suggest that cytokines such as IFN- $\gamma$ provide the mechanism whereby epithelial macromoleculer permeability is up-regulated in intestinal inflammation has been found (15).

Effects of cytokines on epithelial damage, restitution and proliferation: Intestinal inflammation is frequently characterized by frank damage to the epithelium. This effect can partially result from the actions of cytokines. Supernatants from activated mucosal T lymphocytes were shown to be cytotoxic for HT29 intestinal epithelial cells grown in culture (16). This effect has been ascribed to the synergistic action of the cytokines tumour necrosis factor-alpha (TNF- $\alpha$ ) and IFN $-\gamma$. While almost all cytotoxicity of the supernatants appeared to be due to the presence of TNF- $\alpha$, when the effects of recombinant TNF- $\alpha$ on cell viability were assessed, the cytokine was capable of causing significant cell death only when given simultaneously with IFN- $\gamma$. Overall, these results point to the potential for cytokine release from activated lymphocytes and other inflammatory cells in the lamina propria to contribute to the epithelial damage seen in inflammatory bowel disease (IBD).

The epithelium can respond to inflammatory damage in two ways. The first is a rapid repair mechanism and involves a process referred to as restitution. In this process, epithelial cells adjacent to damaged areas flatten and migrate to seal epithelial discontinuities. There is evidence that cytokines and growth factors may be regulators of this process. For example, IL-1 has been shown to induce ornithine decarboxylase activity in intestinal epithelial cells (17). Ornithine decarboxylase is a key initial enzyme involved in both restitution and epithelial proliferation (18). Likewise, both EGF and TGF- $\beta$ stimulate migration of epithelial cells over extracellular matrix components $(19,20)$. The effect of EGF appears attributable, in part, to the up-regulation of epithelial integrins (19).

The second way by which the epithelium can respond to damage is by increasing its rate of proliferation. Ultimately this may lead to crypt hyperplasia, a common feature of IBD, because the rate at which enterocytes differentiate may not be able to keep pace with a larger increase in epithelial proliferative capacity.

It is beyond the scope of this article to review in detail the complex networks thought to be responsible for the control of epithelial dynamics in both the normal and diseased intestine (for review see 21). However, it is pertinent to make a few remarks concerning the peptide growth factors that are thought to be primarily responsible for control of

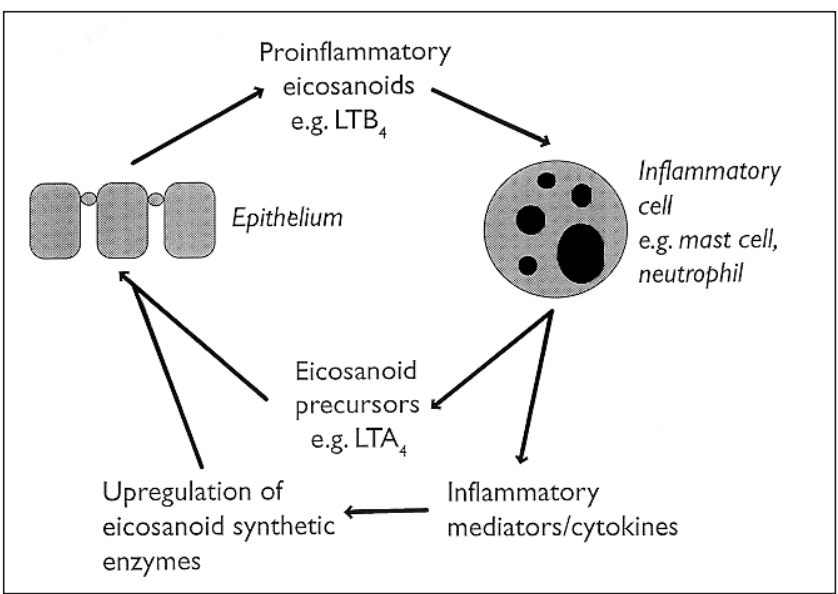

Figure 1) Example of a potential eicosanoid synthetic pathway, involving transcellular cooperation between the epithelium and inflammatory cell types, that may be subject to up-regulation by cytokines. Inflammatory cells can supply leukotriene $\mathrm{A}_{4}\left(\mathrm{LTA}_{4}\right)$ to the epithelium for conversion to the chemotactic lipid $\mathrm{LTB}_{4}$, which would then stimulate further inflammatory cell migration and activation. Inflammatory cells can also supply cytokines capable of specifically up-regulating enzyme (eg, LTA hydrolase) expression, thereby amplifying the loop and allowing a vicious cycle of inflammation

this process. The overall rate of proliferation of the intestinal epithelium appears to reflect a balance between the growth stimulatory factor TGF- $\alpha$ and the growth inhibitory TGF- $\beta$ (21). EGF may also play a stimulatory role in the control of epithelial proliferation, although the importance of this growth factor relative to that of the TGF is not clearly defined. This is because the majority of EGF is secreted into the intestinal lumen where it is subject to significant proteolytic cleavage; moreover, EGF receptors on intestinal epithelial cells appear to be confined to the basolateral membrane domain (22).

Effects of cytokines on the ability of the epithelium to express immune accessory and adhesion molecules: The intestinal epithelium is becoming increasingly recognized as a constituent of the mucosal immune system (23). Intestinal epithelial cells have the capability to present antigen to helper lymphocytes, a property that appears to be specifically up-regulated during inflammation (24). Conversely, epithelial cells from inflamed tissues fail to present antigen effectively to antigen nonspecific suppressor T cells (24). Stimulated intestinal lymphocytes release a cytokine, identified as IFN- $\gamma$, that can induce major histocompatibility class II molecule (HLA-DR) expression on HT29 cultured intestinal epithelial cells (25). Similarly, recombinant IFN- $\gamma$ induces HLA-DR on the surface of the $\mathrm{T}_{84}$ epithelial cell line (26). These findings may relate to the changes in antigen presentation seen in IBD because it was shown that lamina propria lymphocytes from patients with either Crohn's disease or ulcerative colitis displayed significantly higher rates of IFN- $\gamma$ secretion upon stimulation (27).

Cytokines may also be responsible for the regulation of adhesion molecule expression on intestinal epithelial cells. For example, intercellular adhesion molecule-1 (ICAM-1) 


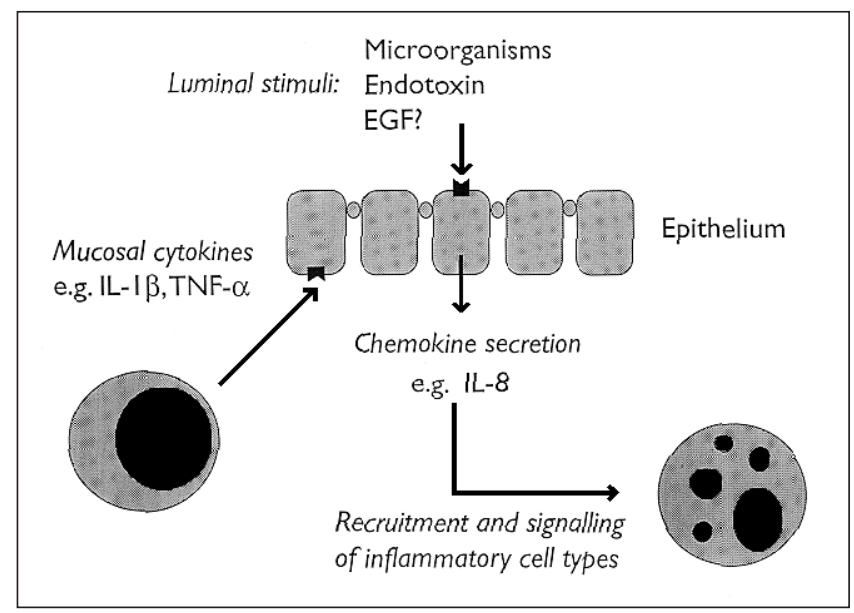

Figure 2) The ability of the epithelium to secrete chemokines and other proinflammatory cytokines may provide a mechanism whereby phagocytes are recruited to a specific mucosal location. The epithelium acts as a source of cytokines. In response to luminal stimuli, such as invasive microorganisms or endotoxin (or possibly epidermal growth factor [EGF]), or in response to mucosal cytokines, intestinal epithelial cells can synthesize the chemotactic cytokine interleukin (IL)-8. This likely results in the recruitment of inflammatory cell types to the site of initial injury or insult, and their subsequent activation. TNF Tumour necrosis factor

expression can be induced on cultured epithelial cells by IFN- $\gamma$, IL-1, TNF- $\alpha$ and IL-6 $(28,29)$. This may have implications for the ability of epithelial cells to orchestrate mucosal immune responses, in that increased ICAM-1 expression promotes the adhesion of activated $\mathrm{T}$ cells via the leukocyte function-associated antigen-1 ligand for this molecule (30). The expression of adhesion molecules on the epithelial surface may also be important for their interaction with other inflammatory cell types. Neutrophils have been shown to adhere to and migrate through $\mathrm{T}_{84}$ epithelial cell monolayers when driven by a chemotactic gradient (31). Neutrophil migration across epithelial monolayers is subject to modulation by IFN- $\gamma$, although the effects seen are qualitatively different depending on the direction of cell migration examined. Thus, IFN- $\gamma$ pretreatment markedly up-regulated transmigration of neutrophils in the apical to basolateral direction (32). However, in the physiologically more relevant basolateral to apical direction for migration, IFN $-\gamma$ actually reduced transmigration (32); the cytokine appeared to upregulate an adhesive interaction between the neutrophils and the basolateral surface of the epithelial cells that enhanced the retention of the inflammatory cell type in the subepithelial space. Colgan and associates (32) speculated that this may result in the accumulation of neutrophils in a location where they would be poised to participate in host defence responses.

Effect of cytokines on the production of inflammatory mediators by the epithelium: Finally, the ability of the epithelium to synthesize proinflammatory mediators and, indeed, cytokines has recently been recognized and is the subject of much active research. These abilities may also be subject to regulation by the cytokine milieu. The epithelium has, for example, been recognized as a potential supplier of proinflammatory eicosanoids. In some cases, synthesis may involve a transcellular metabolic route, where infiltrating inflammatory cells supply the intermediate substrate, leukotriene $\mathrm{A}_{4}$, for conversion to the proinflammatory leukotriene $\mathrm{B}_{4}$ by the intestinal epithelial leukotriene $\mathrm{A}_{4}$ hydrolase (unpublished data). This ability of the epithelium can contribute to a vicious cycle of inflammation, contributing to tissue damage by amplifying inflammatory cell migration (Figure 1). In other cases, the complete enzymatic machinery for the generation of an eicosanoid product may be present within the epithelial cell. It has been shown that the enzyme 12 lipoxygenase is specifically induced in the epithelium of tissue specimens from IBD patients (33). Similarly, epithelial cells express phospholipase $A_{2}$ enzymes responsible for the initial release of arachidonic acid from membrane phospholipids, which then supplies downstream eicosanoid synthetic pathways (34). Arachidonic acid metabolites have also been implicated as second messengers for chloride secretion (35), and an increase in their synthesis may contribute to inflammatory diarrhea. By analogy with other epithelial and nonepithelial systems, it seems reasonable to predict that these various eicosanoid metabolic enzymes may be subject to regulation by cytokines and growth factors. However, with the exception of the observation that TNF- $\alpha$ appears to upregulate phospholipase $\mathrm{A}_{2}$ activity in the cultured human intestinal cell line INT 407 (34), the precise cytokine signals responsible for modulating arachidonic acid metabolism in the epithelium, in vivo or in vitro, remain to be established.

The intestinal epithelium may also serve as a local source of complement components. In vitro analyses of Caco-2 cells showed that these cells were capable of synthesizing biologically active C3, C4 and factor B under control conditions (36). Moreover, the synthesis of each of these molecules was selectively up-regulated by cytokines. C3 production was enhanced by IL- 1 and TNF- $\alpha$, C4 by IL- 6 and IFN- $\gamma$, and factor B by IL-1, IL- 6 and, to a small extent, IFN- $\gamma$ (36). Given the numerical significance of epithelial cells in the intestine, the findings suggest that the epithelium may act as the primary source for complement components involved in mucosal host defence and/or local inflammation.

Epithelial cells have also been shown, at least in in vitro models, to act as a source of proinflammatory and chemotactic cytokines, such as IL-1, IL-6 and IL-8. IL-8 secretion may represent a primitive immune response to a cellular insult, such as that provided by bacterial colonization with invasive bacteria such as Salmonella species (37). Similarly, mucosal cytokines derived from lamina propria mononuclear cells may also signal the epithelium to produce additional cytokines. In the rat intestinal epithelial cell line IEC-6, TGF- $\beta$ and IL-1 have been shown to promote the secretion of IL-6 synergistically $(38,39)$. Likewise, in four human intestinal epithelial cell lines, TNF- $\alpha$, IL-1 and bacterial lipopolysaccharide all serve to up-regulate the synthesis of IL-8 (40). In sum, the ability of the epithelium to secrete chemokines and other proinflammatory cytokines may provide a mechanism whereby phagocytes are recruited to a specific mucosal loca- 
tion (Figure 2). This may be a highly appropriate response if evoked in response to bacterial invasion. However, inappropriate triggering of cytokine secretion may lead to an uncontrolled inflammatory response, perhaps also involving some of the other cytokine regulatory loops described above.

\section{SUMMARY AND CONCLUSIONS}

The intestinal epithelium appears to act as both a target and a supplier of cytokines, properties that may be of particular relevance in the setting of inflammation. In some cases, the precise response displayed by the epithelium to a given cytokine may depend on the intrinsic functional properties of the epithelial cell. Thus, significant information remains to be elucidated regarding the exact details of the highly in-

ACKNOWLEDGEMENTS: I thank Julie Lessem for help with manuscript preparation. I am also grateful to the following former and present colleagues and collaborators for their contributions to the studies from my laboratory that are outlined in this article, and for helpful discussions: Timothy Bigby MD, Cornelia Gelbmann MD, Alexis Traynor-Kaplan PhD, Jorge Uribe MS and Mana Vajanaphanich MD. Studies from the author's laboratory have been supported by grants from the National Institutes of Health (AI 24992 and DK 28305).

\section{REFERENCES}

1. Sartor RB. Cytokines in intestinal inflammation: Pathophysiological and clinical considerations. Gastroenterology 1994;106:533-9.

2. Barrett KE, Dharmsathaphorn K. Secretion and absorption: small intestine and colon. In: Yamada T, ed. Textbook of Gastroenterology. Philadelphia: JB Lippincott Company, 1991:265-94.

3. Stead RH, Perdue MH, Cooke H, Powell DW, Barrett KE, eds. Neuro-Immuno-Physiology of the Gastrointestinal Mucosa; Implications for Inflammatory Diseases. New York: New York Academy of Sciences, 1992.

4. Chang EB, Musch MW, Mayer L. Interleukins 1 and 3 stimulate anion secretion in chicken intestine. Gastroenterology 1990;98:1518-24.

5. Gelbmann C, Eckmann L, Vajanaphanich M, Kagnoff MF, Barrett KE. Dual effects of TGF- $\beta$ on epithelial chloride secretion. Gastroenterology 1992;102:A211.

6. Hinterleitner TA, Berschneider HM, Powell DW. Fibroblast-mediated $\mathrm{Cl}^{-}$secretion by $\mathrm{T}_{84}$ cells is amplified by interleukin-1 $\beta$.

Gastroenterology 1991;100:A690.

7. Opleta-Madsen K, Hardin J, Gall DG. Epidermal growth factor upregulates intestinal electrolyte and nutrient transport. Am J Physiol 1991;260:G807-14.

8. Hardin JA, Buret A, Meddings JB, Gall DG. Effect of epidermal growth factor on enterocyte brush-border surface area. Am J Physiol 1993;264:G312-8.

9. Uribe JM, Gelbmann CM, Traynor-Kaplan AE, Barrett KE. Epidermal growth factor inhibits $\mathrm{Ca}^{++}$dependent $\mathrm{Cl}^{-}$secretion in $\mathrm{T}_{84}$ human colonic epithelial cells. Am J Physiol. (In press)

10. Hiribarren A, Heyman M, 'Helgouac'h AL, Desjeux JF. Effect of cytokines on the epithelial function of the human colon carcinoma cell line HT29 cl 19A. Gut 1993;34:616-20.

11. Adams RB, Palnchon SM, Roche JK. IFN- $\gamma$ modulation of epithelial barrier function. Time course, reversibility, and site of cytokine binding. J Immunol 1993;150:2356-63.

12. McRoberts JA, Riley NE. Regulation of $\mathrm{T}_{84}$ cell monolayer permeability by insulin-like growth factors. Am J Physiol 1992;262:C207-13.

13. Madara JL, Stafford J. Interferon- $\gamma$ directly affects barrier function of cultured intestinal epithelial monolayers. J Clin Invest 1989;83:724-7.

14. McRoberts JA, Aranda R, Riley N, Kang H. Insulin regulates the paracellular permeability of cultured intestinal epithelial cell monolayers. J Clin Invest 1990;85:1127-34.

15. May GR, Sutherland LR, Meddings JB. Is small intestinal permeability really increased in relatives of patients with Crohn's disease? Gastroenterology 1993;104:1627-32. tegrated and redundant network of cytokine-epithelial interactions. Similarly, despite considerable progress in identifying the cytokines that are elevated in the inflamed tissue of IBD patients (1), details of the precise cytokine milieu (both qualitatively and quantitatively) at different stages of the disease process, or in patients who are being treated with various therapeutic modalities, remain to be determined. Nevertheless, information obtained to date regarding the interaction of cytokines with epithelial cells suggests that increased knowledge in these areas may have clinical implications for IBD management. Elucidation of the precise regulatory loops involved may aid our ability to modulate processes such as secretory diarrhea, epithelial restitution and mucosal immunity.

16. Deem RL, Shanahan F, Targan SR. Triggered human mucosal T cells release tumour necrosis factor- $\alpha$ and interferon- $\gamma$ which kill human colonic epithelial cells. Clin Exp Immunol 1991;83:79-84.

17. Chung DH, Evers BM, Townsend CM, et al. Cytokine regulation of gut ornithine decarboxylase gene expression and enzyme activity. Surgery 1992;112:364-9.

18. McCormack SA, Viar MJ, Johnson LR. Polyamines are necessary for cell migration by a small intestinal crypt cell line. Am J Physiol 1993;264:G367-74.

19. Basson MD, Modlin IM, Madri JA. Human enterocyte (Caco-2) migration is modulated in vitro by extracellular matrix composition and epidermal growth factor. J Clin Invest 1992;90:15-23.

20. Ciacci C, Lind SE, Podolsky DK. Transforming growth factor $\beta$ regulation of migration in wounded rat intestinal epithelial monolayers. Gastroenterology 1993;105:93-101.

21. Podolsky DK. Regulation of intestinal epithelial proliferation: A few answers, many questions. Am J Physiol 1993;264:G179-86.

22. Scheving LA, Shiurba RA, Nguyen TD, Gray GM. Epidermal growth factor receptor of the intestinal enterocyte. Localization to laterobasal but not brush border membrane. J Biol Chem 1989;264:1735-41.

23. Mayer L, Shlien R. Evidence for function of Ia molecules on gut epithelial cells in man. J Exp Med 1987;166:1471-83.

24. Mayer L, Eisenhardt D. Lack of induction of suppressor T cells by intestinal epithelial cells from patients with inflammatory bowel disease. J Clin Invest 1990;86:1255-60.

25. Lowes JR, Radwan P, Priddle JD, Jewell DP. Characterisation and quantification of mucosal cytokine that induces epithelial histocompatibility locus antigen-Dr expression in inflammatory bowel disuse. Gut 1992;33:315-9.

26. Meyer L, Eisenhardt D, Salomon P, Bauer W, Plous R, Piccinini L. Expression of class II molecules on intestinal epithelial cells in humans. Gastroenterology 1991;100:3-12.

27. Salomon P, Pizzimenti A, Panja A, Reisman A, Mayer L. The expression and regulation of class II antigens in normal and inflammatory bowel disease peripheral blood monocytes and intestinal epithelium. Autoimmunity 1991;9:141-9.

28. Kvale D, Krajci P, Brandtzaeg P. Expression and regulation of adhesion molecules ICAM-1 (CD54) and LFA-3 (CD58) in human intestinal epithelial cell lines. Scand J Immunol 1992;35:669-6.

29. Kaiserlian D, Rigal D, Abello J, Revillard J-P. Expression, function and regulation of the intercellular adhesion molecule-I (ICAM-1) on human intestinal epithelial cell lines. Eur J Immunol $1991 ; 21: 2415-21$.

30. Springer TA. Adhesion receptors of the immune system. Nature 1990;346:425-34.

31. Nash S, Stafford J, Madara JL. Effects of polymorphonuclear leukocyte transmigration on the barrier function of cultured intestinal epithelial monolayers. J Clin Invest 1987;80:1104-13.

32. Colgan SP, Parkos CA, Delp C, Arnaout MA, Madara JL. Neutrophil migration across cultured intestinal epithelial monolayers is modulated by epithelial exposure to IFN- $\gamma$ in a highly polarized fashion. J Cell Biol 1993;120:785-98.

33. Shannon VR, Stenson WF, Holtzman MJ. Induction of epithelial arachidonate 12-lipoxygenase at active sites of inflammatory bowel disease. Am J Physiol 1993;264:G104-11.

34. Gustafson-Svard C, Tagesson C, Boll R-M, Kald B. Tumor necrosis 


\section{Barrett}

factor- $\alpha$, potentiates phospholipase $\mathrm{A}_{2}$-stimulated release and metabolism of arachidonic acid in cultured intestinal epithelial cells (INT 407). Scand J Gastroenterol 1993;28:323-30.

35. Barrett KE, Bigby TD. Involvement of arachidonic acid in the chloride secretory response of intestinal epithelial cells. Am J Physiol 1993;264:C446-52.

36. Andoh A, Fujiyama Y, Bamba T, Hosoda S. Differential cytokine regulation of complement $\mathrm{C} 3, \mathrm{C} 4$, and factor $\mathrm{B}$ synthesis in human intestinal epithelial cell line, Caco-2. J Immunol 1993;151:4239-47.

37. Eckmann L, Kagnoff MF, Fierer J. Epithelial cells secrete the chemokine interleukin- 8 in response to bacterial entry. Infect Immunol 1993;61:4569-74.
38. McGee DW, Beagley KW, Aicher WK, McGhee JR. Transforming growth factor $-\beta$ and IL-1 $\beta$ act in synergy to enhance IL- 6 secretion by the intestinal epithelial cell line, IEC-6. J Immunol 1993;151:970-8.

39. McGee DW, Beagley KW, Aicher WK, McGhee JR. Transforming growth factor- $\beta$ enhances interleukin- 6 secretion by intestinal epithelial cells. Immunology 1992:77:7-12.

40. Eckmann L, Jung HC, Schurer-Maly C, Panja A, MorzyckaWroblewska E, Kagnoff MF. Differential cytokine expression by human intestinal epithelial cell lines: regulated expression of interleukin 8. Gastroenterology 1993;105:1689-97. 


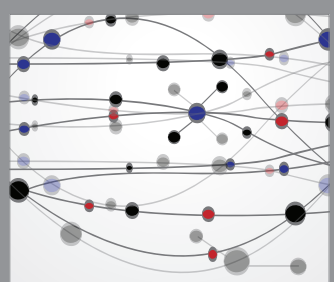

The Scientific World Journal
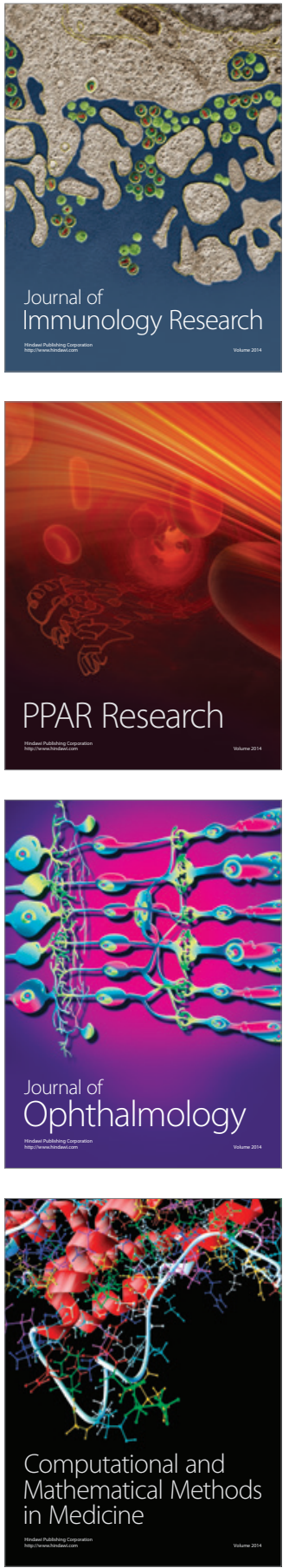

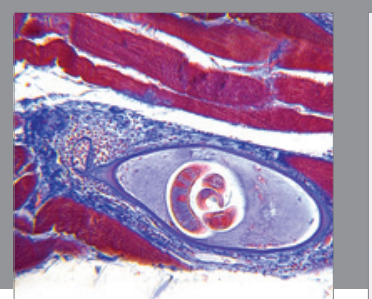

Gastroenterology Research and Practice

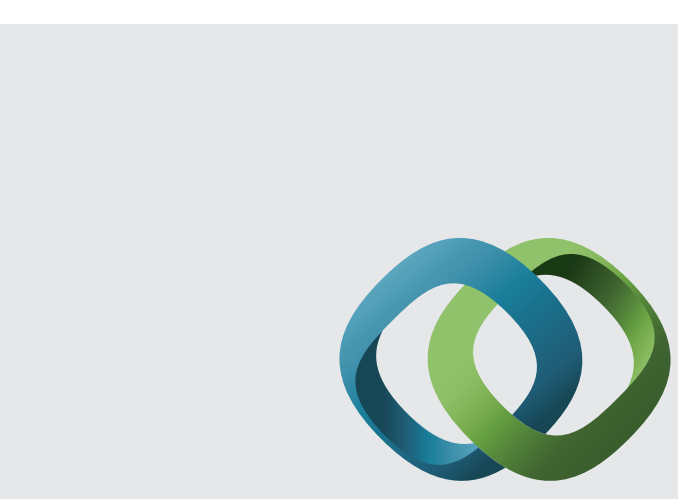

\section{Hindawi}

Submit your manuscripts at

http://www.hindawi.com
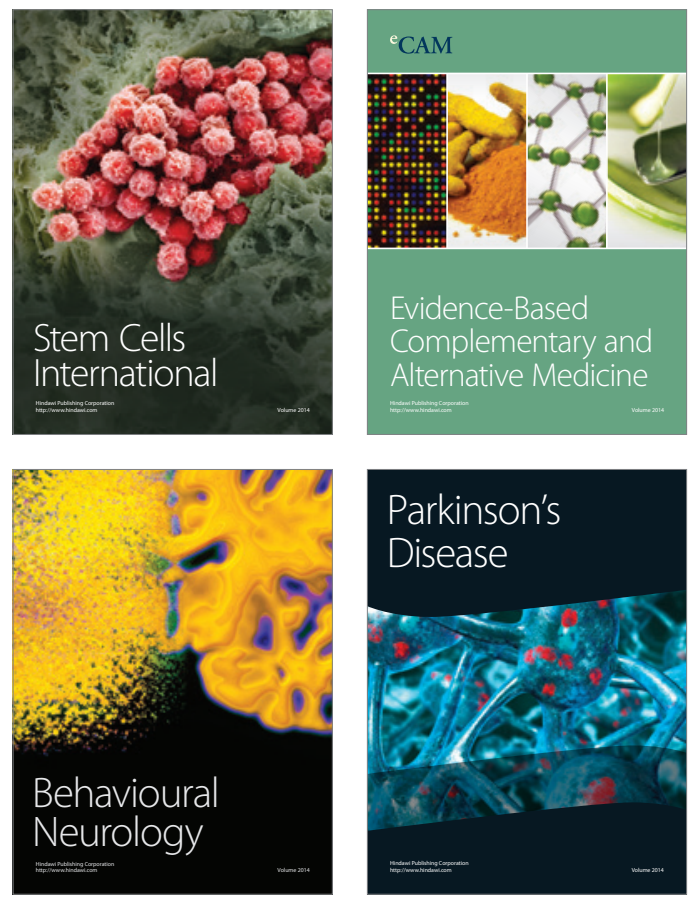
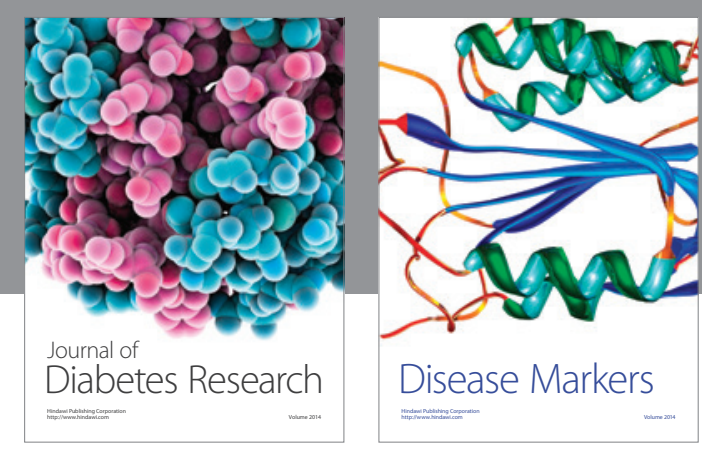

Disease Markers
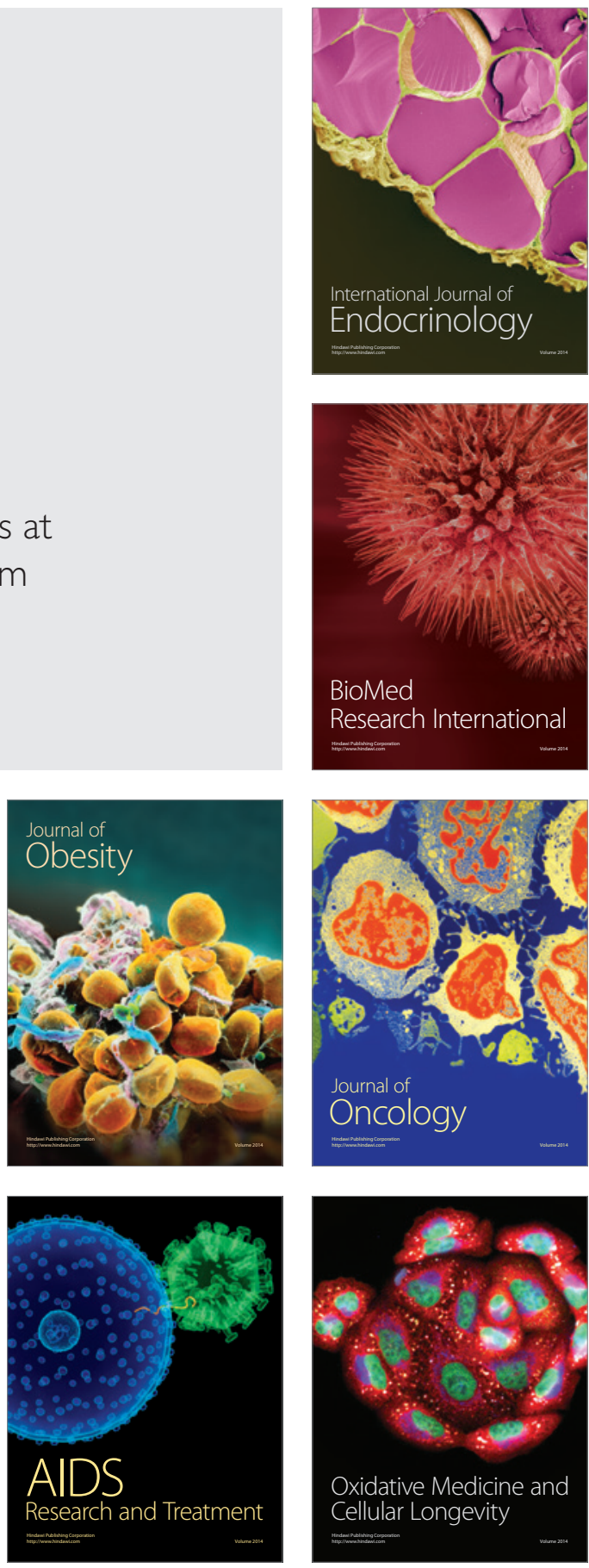